\title{
LA ATENUACIÓN EN LA PRODUCCIÓN DE ACTOS DE HABLA EN HABLANTES NATIVOS Y NO NATIVOS DE ESPAÑOL
}

MITIGATION IN SPEECH ACT PRODUCTION IN NATIVE AND NON-NATIVE SPEAKERS OF SPANISH

\section{Raquel Hidalgo Downing}

Universidad Complutense de Madrid

Resumen:

En este artículo se presentan los resultados de un estudio que compara la producción de determinados actos de habla en hablantes nativos y no nativos de español. Para ello, se ha seguido una metodología de recolección de datos basada en una serie de role-plays cerrados en los que los informantes han de mostrar reacciones o respuestas no preferidas, es decir negativas o de rechazo, a las situaciones comunicativas dadas. El estudio plantea que tanto nativos como no nativos emplean estrategias pragmáticas para expresar los actos, en particular estrategias de atenuación (mitigación o intensificación), pero estas varían tanto en la cantidad como en el tipo de mecanismos empleados por los hablantes nativos y no nativos. En el trabajo se exploran los factores que determinan el uso de los mecanismos de atenuación, así como las implicaciones para el estudio de la interlengua pragmática.

PALABRAS CLAVE: atenuación, actos de habla, pragmática, interlengua pragmática
Abstract

In this article we discuss the results of a study where we compare the production of speech acts in native and non-native speakers of Spanish. We have collected the data following a closed-role play protocol where the informants had to react to speech situations producing dispreferred or negative reactions. The study shows that both native and nonnative speakers plan out and use mitigation (mitigation or intensification) strategies in order to produce dispreferred responses, although these vary in number and variety in native and nonnative speakers. In the discussion, we explore factors determining mitigation strategies, and we also forward implications for the study of pragmatic interlanguage.

KEY WORDS: mitigation, speech acts, pragmatics, pragmatic interlanguage 


\section{INTRODUCCIÓN}

En este artículo estudiamos las similitudes y diferencias en la realización de actos de habla, producidos por hablantes nativos y no nativos de español. Para ello, se sigue una metodología de recolección de datos basada en el diseño de una serie de situaciones comunicativas a las que los informantes han de reaccionar, produciendo una respuesta o continuación no preferida, es decir, de negativa, rechazo o desacuerdo. En los estudios sobre pragmática desde un enfoque contrastivo o intercultural (Blum-Kulka, Kasper y House 1989, Brown y Levinson 1987, Sifianou 1992), se pone de manifiesto que los hablantes producen los actos de habla siguiendo distintos tipos de estrategias, la estrategia directa o indirecta, en distintos grados, y esta elección depende de un complejo conjunto de factores, tanto lingüísticos como sociales y culturales, que constituyen un componente importante de la competencia pragmática de los hablantes, es decir, de su capacidad para analizar adecuadamente los parámetros sociales y comunicativos y reaccionar de acuerdo a esos parámetros. En el análisis de la conversación, por otro lado, se denomina respuesta no preferida (o despreferida) a la segunda parte de un par adyacente que plantea un rechazo o negativa a lo solicitado por el hablante, lo que exige por su parte una mayor elaboración lingüística, toda vez que la respuesta negativa supone riesgos interpersonales para las imágenes de los interlocutores (Levinson, 1983). En este trabajo, por tanto, se ha escogido estudiar este tipo de respuestas porque pueden ser particularmente interesantes para analizar los procesos de elaboración pragmalingüística que exigen los actos de habla, y estudiar el funcionamiento y los factores que configuran la competencia pragmática de los hablantes, así como su producción.

En cuanto a los datos escogidos, el estudio de la competencia pragmática de los hablantes no nativos constituye un área de sumo interés en la pragmática y la adquisición de lenguas extranjeras, ya que no ha sido explorado de forma exhaustiva. En la interlengua pragmática de los hablantes no nativos del español, el propósito en este estudio es conocer si los hablantes no nativos emplean las mismas estrategias que los nativos, si muestran conciencia pragmática en el uso de esas estrategias, o si por el contrario se advierte fallo pragmático.

El artículo se propone, por tanto, (i) describir los procesos de elaboración pragmalingüística de respuestas no preferidas, (ii) comparar las estrategias de realización de estos actos en hablantes nativos y no nativos, e (iii) indagar en el concepto de conciencia pragmática y competencia pragmática de los hablantes.

El artículo se presenta en dos partes principales, la revisión del marco teórico y el análisis de los datos, organizado en 6 secciones. En las secciones 1, 2 y 3 se presenta el marco teórico del trabajo: en la sección 1 se aporta una breve revisión de los estudios sobre el acto de habla desde el enfoque comparado e intercultural; en la sección 2, se expone el concepto de atenuación y el modo en que se ha estudiado en la lengua; en la sección 3, por último, se pone en relación lo anterior con la idea de la interlengua pragmática y de los estudios con enfoque adquisicional. La segunda parte del trabajo introduce la metodología empleada en el estudio (sección 4) y una presentación detallada y discusión de los resultados obtenidos (secciones 5 y 6). El trabajo se completa con las conclusiones y la bibliografía. 
La atenuación en la producción de actos de habla en hablantes nativos y no nativos de español | Raquel Hidalgo

\section{LOS ACTOS DE HABLA DESDE UNA PERSPECTIVA INTERCULTURAL}

El estudio de los actos de habla en relación con la dimensión contextual y cultural constituye una de las áreas de investigación más importantes en la pragmática (Brown y Levinson 1987, Blum-Kulka 1987, Blum-Kulka, Kasper y House 1989, Wierzbicka 1996, Placencia y Bravo 2002). La variación en la producción de los actos de habla se ha relacionado con frecuencia con la cortesía, alegando que el carácter directo o indirecto de los actos de habla se debe a la necesidad de atender los juegos de imágenes de los interlocutores, así como las normas de cortesía de una lengua-cultura determinada (Brown y Levinson 1987, Blum-Kulka 1987, Escandell Vidal 1995). La interacción entre actos de habla y la dimensión cultural se ha abordado desde al menos tres aspectos fundamentales: (i) la formulación de los actos de habla en las distintas lenguas, (ii) la institucionalización de los actos indirectos, y (iii) los patrones conversacionales. En otras palabras, se ha estudiado la variación en la producción de los actos de habla en las lenguas, así como en las convenciones de forma y uso que configuran los actos indirectos. Por otro lado, los actos se integran asimismo en la conversación, pero las culturas poseen patrones conversacionales distintos, por ejemplo en los temas, formas de tratamiento o convencionalización de determinadas rutinas conversacionales.

En los estudios que abordan la distinción entre actos directos e indirectos, se señala que los hablantes pueden escoger realizar el acto de habla de forma directa, es decir, expresando la intención comunicativa con la forma lingüística explícita para esa función (Blum-Kulka 1987, Márquez Reiter 2000, Sifinaou 1992, Havertake 2004):

(1) Déjame un bolígrafo, por favor.

La estrategia indirecta sería aquella, en cambio, en la que se ejecuta el acto de forma indirecta, es decir a través de otro acto, pero empleando una serie de formas (convenciones de forma) que se han fijado para la expresión de ese acto de habla (convenciones de uso):

(2) ¿Le importaría dejarme un bolígrafo, por favor?

(3) Me gustaría un bolígrafo.

Por último, en la estrategia indirecta no convencional, el hablante realiza el acto de habla mediante otro acto, cuyo uso no está convencionalizado:

(4) No tengo con qué escribir.

La elección de unas estrategias sobre otras se relaciona con los parámetros contextuales y culturales, como la relación entre los interlocutores y el grado de imposición del acto, ambos aspectos susceptibles, naturalmente, de variación cultural (Havertake 2004, Hickey 1991, Lorenzo Dus 2001, Márquez Reiter 2000).

Además, se entiende que en la realización de los actos, existen respuestas preferidas y no preferidas para los hablantes. Mientras que las primeras no suponen riesgos en la interacción y se ejecutan con formas simples y claras (acuerdo, aceptación), las segundas plantean una mayor dificultad para el hablante, lo que se plasma en mayor longitud y complejidad lingüística; por esta razón, las respuestas no preferidas suelen ser largas y no 


\section{normas}

La atenuación en la producción de actos de habla en hablantes nativos y no nativos de español | Raquel Hidalgo

se ejecutan mediante un solo actos, sino que van precedidos o seguidos de actos complementarios (Geluykens y Breuer, 2007).

\section{PROCEDIMIENTOS DE ATENUACIÓN EN LA REALIZACIÓN DE ACTOS DE HABLA}

En los últimos años, se ha producido un interés creciente en la lingüística por el estudio de la atenuación (Briz 2005, Ballesteros 2002, Caffi 2007, Albelda et al. 2014,), entendida esta como "una estrategia lingüística de distanciamiento del mensaje con el fin de acercarse o no alejarse demasiado del otro y, de ese modo, obtener su aceptación" (Albelda et al., 2014: 9). A través de los distintos procedimientos de atenuación, los interlocutores logran modular sus enunciados para poder alcanzar de un modo más eficiente sus objetivos comunicativos, en una estimación de la relación entre los interlocutores para que se produzca sintonía, adaptación o attunement (Caffi, 2007: 7) entre ellos a lo largo de la interacción: "in everyday life, mitigation indexes the speaker's attempt to tune in to his/her interlocutor". La atenuación "incide en el discurso de dos maneras, o bien minimizando la fuerza ilocutiva de los actos de habla, bien reduciendo (desfocalizando) el papel de los participantes en la enunciación" (Albelda et al., 2014: 9). En el estudio de la atenuación como fenómeno pragmático ha de distinguirse las funciones de los procedimientos de la misma. Los interlocutores emplean estrategias de atenuación para adaptarse mejor a las necesidades de la interacción en cuanto a la relación interpersonal, y por tanto las (macro) funciones a las que esta responde, tienen que ver con los efectos de la interacción sobre los interlocutores, como la auto-protección, la prevención y la curación o reparación (Albelda et al., 2014: 16). De forma similar, para Caffi (2007) los interlocutores emplean la mitigación con dos propósitos fundamentales: la efectividad interaccional, es decir, la necesidad de alcanzar determinadas finalidades comunicativas, y la construcción de la identidad, es decir, la modulación de la relación entre los interlocutores, ya sea de crear distancia entre ellos o de acercarlos afectivamente (Caffi, 2007: 94).

Por otro lado, se distinguen los procedimientos de atenuación, es decir los recursos lingüísticos (o paraverbales o incluso no verbales) que emplean los interlocutores para atenuar, tanto a nivel ilocutivo (actos de habla) como locutivo: "en algunos casos la atenuación se revela mediante procedimientos proposicionales (esto es, el atenuante afecta directamente a algún elemento del dictum) y otras veces mediante procedimientos que afectan directamente a la enunciación (al modus)" (Albelda et al., 2014: 23). Los mecanismos de atenuación pueden ser, efectivamente, léxicos o morfológicos (diminutivos, cuantificadores), sintácticos (determinadas construcciones, como "es que", construcciones que se emplean para actos de habla).

Caffi (2007) identifica al menos tres niveles: proposicional (los procedimientos de mitigación internos de la proposición), ilocutiva (los actos de habla indirectos, y los mtigadores que suavizan o disminuyen la fuerza ilocutiva del acto) y la deíctica, que incide sobre el origen deíctico de la interacción, es decir sobre los interlocutores (Caffi, 2007: 95).

En la última década, se han ido ampliando los datos sobre los que se ha estudiado la atenuación, como el análisis contrastivo (Ballesteros, 2002), el habla entre mujeres (Álvarez Muro y Joven Best, 2005), la conversación coloquial (Briz, 2005), el intercambio médico (Caffi, 2007), los aprendices de español (Félix-Brasdefer, 2010). 


\section{LA INTERLENGUA PRAGMÁTICA}

El análisis de las producciones de actos en hablantes nativos y no nativos posee implicaciones para el estudio de la interlengua pragmática (Kasper y Blum-Kulka 1993, Kraft y Geluykens 2008), un campo de estudio de enorme interés y complejidad, ya que resulta difícil aislar los elementos específicos de la competencia pragmática del dominio léxico y gramatical; es decir, la producción de las estrategias pragmáticas puede verse limitada por la falta de dominio lingüístico (Zufferey 2015, Kasper y Blum-Kulka 1993, Houck y Gass 1995). En los estudios sobre adquisición y aprendizaje de segundas lenguas, se entiende que la competencia pragmática abarca distintos componentes y habilidades, como la competencia ilocutiva, entendida como la capacidad para producir e interpretar adecuadamente los actos de habla, la competencia sociolingüística, que correspondería a la habilidad para ajustar la producción a los parámetros contextuales y sociales de la situación, y la competencia interaccional, que resultaría en la capacidad para emplear los patrones conversacionales de una lengua (Lorenzo Dus y Meara, 2004). Si bien la interlengua pragmática es un campo de estudio que despierta enorme interés y posee importantes implicaciones para la enseñanza, no son tantos los estudios detallados y sobre datos empíricos que puedan servir pedagógicamente para acometer áreas concretas de la gramática y pragmática del aprendizaje de una lengua. Por eso, en esta investigación es mi propósito aplicar la sólida tradición en el estudio de los actos de habla desde un punto de vista intercultural a la adquisición de los mismos en aprendices del español. Por otro lado, los procesos y mecanismos de atenuación constituyen modos naturales que tienen los hablantes para expresarse en determinadas situaciones comunicativas, y constituyen una muestra indudable de la competencia pragmática del hablante, es decir de su capacidad para modular el discurso. El modo en que esas estrategias se producen en los aprendices de español es una cuestión que está por explorar, y por ello se acomete en esta investigación, con el objetivo de comprender mejor los procesos de adquisición pragmática.

\section{DATOS Y METODOLOGÍA DE TRABAJO}

En este trabajo se ha adoptado una metodología de carácter empírico y cualitativo, y se ha creado un corpus de datos obtenidos de los 30 cuestionarios que constan de varios roleplays cerrados, o situaciones comunicativas, que se han distribuido a 15 informantes nativos y 15 informantes no nativos de español. Los informantes son estudiantes de la Facultad de Filología de la Universidad Complutense de Madrid, 20 mujeres y 10 hombres, de edades comprendidas entre 20 y 30 años, de nacionalidad española los 15 informantes nativos, y los informantes no nativos proceden de Italia, Alemania, Lituania, Rusia, Ukrania, Corea del sur, China, Turquía, Benín (África), y sus lenguas maternas son italiano, alemán, lituano, ruso, ucraniano, coreano, chino, turco, beninés, respectivamente. El nivel de español de los estudiantes no nativos es intermedio avanzado (B.2.2.) y avanzado (C.1.). Los cuestionarios se han recogido en los meses de enero y febrero de 2016.

El cuestionario contiene la relación de cuatro situaciones comunicativas en forma de closed-role play (Félix-Brasdefer, 2010) a la que el informante ha de contestar o completar, ofreciendo una reacción o continuación a la situación. Los informantes han de poner por escrito, en primer lugar, sus pensamientos, es decir, lo que piensan en un primer momento al escuchar la situación comunicativa, y a continuación, han de escribir lo que dicen en esa 
situación. Esta metodología aparece descrita en Kasper (2000), Kasper y Dahl (2002) y Geluykens y Breuer (2007), que denominan "read out protocol" y que sostienen puede emplearse cuando es necesario obtener datos sobre determinados actos de habla, 0 reacciones a actos de habla, que resultan difíciles de encontrar en los corpora de conversación espontánea.

En cuanto a la inclusión de los procesos de pensamiento o "thought processes", estos se describen en la teoría de los actos de habla como los actos o secuencias preparatorias (Searle 1969, Thomas 1996) para la realización de determinados actos de habla y reflejan la reacción inmediata o espontánea del hablante, pero no necesariamente la elaboración del acto de habla que habrá de producirse, puesto que este estará sujeto a las restricciones sociales que marque la cultura en cuestión, y que con frecuencia se enmarcan en la elaboración de la cortesía verbal o gestión de las relaciones interpersonales. Así pues, la distinción entre uno y otro nos permitirá observar la atenuación como un proceso intrínseco a la elaboración del acto de habla en su versión dicha (y no pensada), por tanto en la relación entre el acto y las restricciones socio-culturales, que es lo que da lugar finalmente al acto de habla.

Las cuatro situaciones comunicativas que se ofrecen en el cuestionario plantean al informante que ha de reaccionar el acto de queja (situación 1), el rechazo a un ofrecimiento (situación 2), desacuerdo/rechazo a un ofrecimiento (situación 3), desacuerdo (situación 3) y rechazo a una invitación (situación 4).

Situación 1. No es la primera vez que se oye música muy alta desde el apartamento de tu vecino/a muy tarde por la noche.

Situación 2. Trabajas en un periódico y hay rumores de despidos. Un compañero tuyo ha pensado un plan para que tú y él/ella podáis evitar el despido pero que perjudica directamente a otros.

Situación 3. Estás de compras con una amiga. Ella se está probando una blusa rosa que está pensando en comprarse. Tú crees que no le queda nada bien.

Situación 4. Una persona con la que estás empezando a salir te quiere dar una sorpresa romántica: te ha comprado una entrada para un concierto, pero es un cantante/grupo que a ti no te gusta nada.

Las situaciones plantean distintos parámetros contextuales, en las tres dimensiones poder, distancia y grado de imposición, tal y como describen Brown y Levinson (1987) y Geluykens y Brauer (2007). Las situaciones comunicativas que se han recogido reflejan situaciones cotidianas en las que se pueden encontrar los estudiantes en su vida diaria, y recogen principalmente relaciones entre compañeros o amigos, con una relación igualitaria en cuanto a la dimensión del poder, y con grados variables de familiaridad e imposición del acto, desde la familiaridad que existe entre amigos, hasta la intimidad. La tabla 1 recoge la relación entre las situaciones comunicativas y los parámetros contextuales de los cuatro role-plays: 


\section{normas}

La atenuación en la producción de actos de habla en hablantes nativos y no nativos de español | Raquel Hidalgo

Tabla 1. Relación entre la relación entre las situaciones comunicativas y los parámetros contextuales de los role-plays

\begin{tabular}{|c|c|c|c|c|}
\hline Situación/Variable & Poder & Distancia & $\begin{array}{l}\text { Grado } \\
\text { imposición }\end{array}$ & de \\
\hline Situación 1 & Simétrico (iguales) & Media (conocidos) & Baja & \\
\hline Situación 2 & Simétrico (iguales) & Baja & Media & \\
\hline Situación 3 & Simétrico (iguales) & Baja & Baja & \\
\hline Situación 4 & Simétrico (iguales) & Baja & Baja/Media & \\
\hline
\end{tabular}

\section{RESULTADOS Y DISCUSIÓN}

En esta sección se recogen los resultados del estudio, a partir de la descripción de cada una de las cuatro situaciones, mientras que en la sección siguiente se extraen algunas observaciones comparativas sobre el comportamiento de hablantes nativos y no nativos. En todas las situaciones se han planteado dos pasos: lo que piensan, y lo que dicen. En el primero, han de escribir la reacción inmediata que les produce la situación. Después, han de escribir lo que dicen realmente en la situación dada.

\subsection{Situación 1}

La Situación 1 plantea un role-play en el que los informantes tienen que reaccionar a una molestia causada por un vecino, de modo que se trata de una relación de familiaridad media; el grado de imposición del acto puede ser bajo o medio, según algunos parámetros como la edad o la relación previa entre vecinos (tanto del vecino que causa la molestia como del que se queja).

Tabla 1. Estrategias empleadas por los informantes nativos en la situación 1.

\begin{tabular}{|l|l|l|l|l|}
\hline Nativos & Lo que piensan & \multicolumn{2}{l|}{ Lo que dicen } \\
\hline Directa & 13 & $87 \%$ & 3 & $20 \%$ \\
\hline Indirecta convencional & 1 & $6,5 \%$ & 9 & $40 \%$ \\
\hline Indirecta no convencional & 1 & $6,5 \%$ & 3 & $20 \%$ \\
\hline Total & 15 & 100 & 15 & 100 \\
\hline
\end{tabular}

Los hablantes nativos reaccionan expresando molestia, queja, evaluación negativa del sujeto responsable de la situación de forma directa. Los enunciados de los hablantes en el apartado de "lo que piensan" reflejan las emociones y reacción inmediata ante la situación: como puede verse en la tabla 1, el $87 \%$ de los informantes nativos expresa su reacción de forma directa, y con frecuencia emplean intensificadores, que aumentan la carga expresiva de la emoción negativa y la expresión de la molestia o queja:

(7) Joder, ya está con la musiquita de los huevos, menudo gilipollas.

(8) ¡Me cago en todo, qué pesados son! 
(9) Joder, ¿otra vez? No me lo puedo creer. A ver qué le digo.

El insulto y el empleo de expresiones malsonantes (me cago en todo, joder, menudo gilipollas) intensifican la evaluación negativa y expresan las emociones del hablante. El carácter expresivo del acto de reacción a la situación 1 queda patente en el uso de construcciones exclamativas (qué pesados son) e interrogativas (¿otra vez?). También son construcciones típicas del acto de la queja "ya está con la musiquita", "ya está otra vez" o "no me lo puedo creer". Podemos considerar que son expresiones cuyo uso se ha convencionalizado parcialmente para expresar este tipo de actos, y se reconocen como formas de queja. En ocasiones, los informantes también refuerzan la queja con actos complementarios, como la amenaza, que intensifica la fuerza de la queja:

(10) ¡Otra vez está éste idiota con la música! Voy a bajar a decirle cuatro cosas, ¡va a ir él y su equipo de música cerca, sí!

(11) Me cago en el puto vecino, estoy hasta los cojones de él. ¡Voy a llamar a la policía!

En ocasiones, expresan comentarios sobre la línea de acción que van a seguir, o bien se plantean qué estrategia pragmática han de emplear, expresando en alto la conciencia pragmática, es decir, la necesidad de elaboración pragmalinguistica que exige la situación, la necesidad por tanto de pensar en una estrategia comunicativa adecuada a la situación pero que sea también eficaz para solucionar la misma.

(12) Joder, ¿otra vez? No me lo puedo creer. A ver qué le digo.

(13) ¿Otra vez? Me tiene harta. ¿Es que no sabe que algunos madrugamos? Voy a decirle algo a ver si para, y si sigue, llamo a la policía.

En lo que dicen, en cambio, los hablantes nativos solo son directos en un $20 \%$ de los casos, y prefieren en cambio la estrategia indirecta convencional en un 40\%, y la indirecta no convencional en un $20 \%$. Se advierte, por tanto, un reparto mayor que en los actos pensados.

Cuando se expresan mediante formas directas, los hablantes emplean procedimientos de mitigación:

(14) Por favor, baja la música que no es la primera vez que pasa esto y ya molesta.

(15) Por favor, baja la música, tío, no es la primera vez que pasa.

(16) Oye, perdona, son las 3 y media... Baja un poco la música o algo porque es que se te oye desde el portal.

En los tres casos, los hablantes nativos emplean la forma directa "baja la música" y mitigan el impacto de la petición directa con operadores de cortesía (por favor), alertadores (oye, perdona), apelativos (tío) y actos de habla de apoyo, como la justificación (no es la primera vez que pasa, es que se te oye desde el portal). Como mitigadores internos emplean "un poco" y "o algo". 
La forma más extendida de elaboración, sin embargo, es la petición indirecta convencional. Es esta una forma mitigada de la petición directa, a través fundamentalmente de las formas interrogativas:

(17) Perdona, ¿te importaría bajar la música? Son las tres de la madrugada y mañana tengo que ir a trabajar. Además no es la primera vez que pasa esto, si sigues así voy a llamar a la policía.

(18) Hola, buenas noches ¿Perdone? Podría bajar la música, por favor, es muy tarde y me resulta imposible dormir con su música. No es la primera vez, como vuelva a ocurrir llamo a la Policía.

(19) Perdona, pero sería tan amable de bajar la música. No son horas de tenerla tan alta.

En esta estrategia, los hablantes emplean la mitigación ilocutiva, puesto que emplean la petición indirecta como forma para expresar el acto. Pueden encontrarse los distintos grados de "indirectez", desde la interrogativa, “¿te importaría bajar la música?”, en general con formas que marcan distancia como el uso del condicional (importaría) y verbos como "importar". También aparece las oraciones declarativas, "me gustaría pedirle", que se consideran un grado más indirecto, de mayor mitigación, que la interrogativa. Acompañan el acto nuclear actos de apoyo como la justificación, "es que se escucha la música por toda mi casa y mañana tengo que madrugar", "porque mañana tengo que levantarme muy pronto para ir a clase y con el ruido soy incapaz de dormir", que aportan fuerza a la petición. El propósito mitigador de los actos de refuerzo se plasma en el hecho de que el hablante los utiliza para aportar argumentos a la razonabilidad de su petición, con lo que intenta aludir a los "derechos y obligaciones" de los interlocutores en la convivencia social, y en la que, por tanto, ese contrato y cumplimiento de nuestros derechos y obligaciones, está por encima de las necesidades individuales de imagen de cada uno de los interlocutores.

La diferencia entre los actos pensados y los actos dichos es patente: en los pensamientos, los hablantes expresan sus reacciones inmediatas, y por tanto son respuestas que remiten a sus emociones, como actos expresivos, evaluación negativa, queja, insulto. En los actos dichos, en cambio, los hablantes realizan una elaboración lingüística a través de la petición. Solo en dos casos lo que dicen es similar a lo que piensan, expresando una queja (qué pesados) también en lo que dicen.

Por tanto, esta diferencia sugiere que los hablantes poseen conciencia pragmática, es decir, sienten que la producción ha de satisfacer determinados requisitos contextuales y sociales. Además, la competencia pragmática de los hablantes les permite efectivamente modular esas emociones iniciales, para lograr su objetivo (que el vecino baje la música) y no simplemente expresar la molestia o desagrado ante la situación. La variación entre uno y otro muestra esa canalización de las emociones hacia estrategias comunicativas convencionales. Además, la elaboración lingüística y preferencia por estrategias indirectas con mitigadores sugiere que el grado de imposición del acto es medio, y no bajo, puesto que los hablantes muestran la necesidad de mostrarse razonables y corteses a la hora de realizar la queja en forma de petición. 
La atenuación en la producción de actos de habla en hablantes nativos y no nativos de español | Raquel Hidalgo

Tabla 2. Estrategias empleadas por los informantes no nativos en la situación 1.

\begin{tabular}{|c|c|c|c|c|}
\hline No Nativos & \multicolumn{2}{|c|}{ Lo que piensan } & \multicolumn{2}{|c|}{ Lo que dicen } \\
\hline Directa & 12 & $80,5 \%$ & 5 & $33 \%$ \\
\hline Indirecta convencional & 1 & $6,5 \%$ & 7 & $47 \%$ \\
\hline Indirecta no convencional & 2 & $13 \%$ & 3 & $20 \%$ \\
\hline Total & 15 & 100 & 15 & 100 \\
\hline
\end{tabular}

Los hablantes no nativos expresan lo que piensan como queja directa en un $80,5 \%$ de los casos, es decir, en clara mayoría también, si bien algo menos que los nativos (7\% menos). Reaccionan con la queja o evaluación negativa de forma directa con intensificadores ilocutivos (insultos) e internos (la puta música), utilizan la expresión "otra vez con..." pero no utilizan construcciones como "ya está el vecino", como tampoco utilizan diminutivos (musiquita), pero sí complementos o adjetivos (intensificadores internos). Emplean asimismo actos de apoyo que intensifican la queja, como la amenaza:

(20) La madre...... otra vez, ya no aguanto más con él.

(21) Maldita sea. Otra vez con la puta música. Llamo a la policía.

(22) ¡Qué pesado!

(23) ¡Qué mala educación, siemple pone música alta por la noche. Estoy hasta la nariz, ¡tengo que hablar con ellos!

(24) ¡Otra veeeez! Odio a mis vecinos!!!

También se encuentran casos en los que el informante no emplea una estrategia directa; evalúa negativamente la situación, pero de forma mitigada, y no se detecta una línea de acción clara:

(25) Me molesta mucho para dormir .El vecino es demasiado joven y va a pagarlo caro. Van a quejarse muchos vecinos. Puedo practicar la audición. Como la música no está mal, puedo no criticar al vecino, ya que siempre soy más tolerante que otros vecinos.

(26) Que es una falta de respeto

Es destacable también entre los no nativos la presencia de comentarios meta-pragmáticos que avanzan el curso de acción, y que preparan por tanto la secuencia de actos dichos:

(27) ¡La música todo el volumen! ¡Qué vergüenza! Me voy a quejar.

(28) Voy a subir y decírselo.

A veces expresan conciencia pragmática; la estrategia es similar a la de los nativos, pero la ejecución refleja menor variedad de vocabulario, no utilizan las estructuras identificadoras de la queja, salvo el insulto o la evaluación negativa. 
En los actos dichos, los no nativos emplean una estrategia similar a los actos pensados, se asemeja mucho más lo que dicen a lo que piensan que en los nativos. Así pues, emplean la queja de nuevo, con estructuras similares a los actos pensados:

(29) ¡Madre mía! ¿Esa gente piensa que vive solo en este edifico? Pues no. Voy ahora mismo arriba a tocarles el timbre y hablar con esa gente.

(30) Perdona, sabes qué hora es ahora? Hasta cuándo tengo que soporta esta música que se oye desde el extremo de esta calle? bajas la música o llamo a la policía.

(31) ¡YA NO PUEDO MÁS!

(32) Oye, ¿tú piensas que es normal lo que estás haciendo? ¡Eso ya no es soportable lo que estás haciendo en esta hora! Algunos tenemos que levantar por la mañana.

En estos enunciados, los hablantes no nativos expresan la queja y evaluación de forma casi idéntica al acto pensado, sin apenas modificación entre uno y otro, o bien emplean formas de intensificación (la amenaza, bajas la música o llamo a la policía), lo que puede ser percibido por el vecino como descortés o agresivo, incluso claramente confrontacional. Los hablantes no nativos no emplean aquí las formas indirectas de petición que sí emplean los nativos de español, lo que puede deberse a transferencia pragmática de sus lenguas maternas. Puede considerarse que el acto es percibido como de mayor imposición para los hablantes nativos (precisan de mayor elaboración de cortesía) que para los no nativos (emplean la queja directa). Por otro lado, refleja también que los no nativos no conocen estrategias mitigadoras de la queja, como la petición indirecta.

\subsection{Situación 2}

La Situación 2 plantea un role-play en el que el informante ha de reaccionar a la proposición de un compañero de trabajo, que resulta perjudicial para los demás y que por tanto es difícil de aceptar.

Tabla 5. Estrategias empleadas por los informantes nativos en la situación 3.

\begin{tabular}{|c|c|c|c|c|}
\hline Nativos & \multicolumn{2}{|c|}{ Lo que piensan } & \multicolumn{2}{|c|}{ Lo que dicen } \\
\hline Directa & 9 & $60 \%$ & 7 & $46,5 \%$ \\
\hline Indirecta convencional & 4 & $26,5 \%$ & 6 & $40 \%$ \\
\hline Indirecta no convencional & 2 & $13,5 \%$ & 2 & $13,5 \%$ \\
\hline Total & 15 & 100 & 15 & 100 \\
\hline
\end{tabular}

Al expresar su reacción inmediata, la mayoría de los hablantes nativos (un 60\%) evalúa negativamente a su compañero y reacciona con el rechazo directo al ofrecimiento:

(33) Está mal. Muy mal. No puedo hacerle esto ¿Cómo se le ha ocurrido esa idea tan... tan estúpida? Creo en el karma y es mejor que las cosas sigan su curso.

(34) Menudo con este. Con tal de salvar su culo no le importa pisotear a los demás. 
(35) No me parece bien su plan. Deberíamos encontrar otra solución.

Para ello, los informantes se sirven de intensificadores que aumentan la fuerza negativa del rechazo, como "muy mal", la repetición, (está mal, está muy mal) y evaluaciones negativas, "menudo con este", "con tal de salvar su culo".

En otros casos, expresan el rechazo de forma directa, "no me parece bien su plan" pero emplean la mitigación, por ejemplo sugiriendo una línea de acción alternativa: "deberíamos encontrar otra solución" (mitigación ilocutiva).

En un 26\% de los casos, los informantes emplean estrategias indirectas; es decir, valoran negativamente la propuesta, pero dan a entender que podría ser aceptada, o expresan, mediante la sugerencia, una línea de acción alternativa. A diferencia del grupo anterior, por tanto, los informantes no manifiestan su posición de forma explícita, o bien esta resulta ambivalente:

(36) Qué papelón madre mía...en verdad me viene bien pero hacerlo es una cerdada.

En lo que dicen, un $46 \%$ de los informantes solamente (del 60\% que lo rechazaba en sus pensamientos) elige rechazar el ofrecimiento de forma directa. Para ello, emplea mitigadores de todos los tipos: alertadores (a ver, mira), actos de habla complementarios que apoyan el rechazo, como la justificación, que aporta los motivos del desacuerdo. También puede acompañar la disculpa, entendida como mitigador del rechazo al ofrecimiento:

(37) A ver, igual funciona, pero no me gusta eso de joder a los demás. Además es que está claro que si nos quejamos es porque sabemos que van a despedir a gente. No sé, hazlo tú si quieres pero yo paso.

(38) Lo siento, pero no me parece bien lo que me ofreces. Todos somos compañeros y si para salvarme yo otra gente sale perjudicada, yo paso.

En un caso, el informante acepta el ofrecimiento de forma directa:

(39) Pues lo hacemos, dudo mucho que los demás se pararan en pensar en nosotros si estuvieran en nuestro caso, además se trata de mi trabajo, no de un grupito de colegio.

Puede considerarse mitigador el marcador "pues", así como el uso del tiempo y modo verbal, mientras que "un grupito de colegio" refuerza el acuerdo.

En las respuestas indirectas, que ascienden a un 40\% de los casos, se expresa la sugerencia como forma implícita de rechazo:

(40) Quizás no sea la solución más adecuada. Podríamos pensar en otro tipo de solución que no perjudique al resto ¿No crees?

(41) ¿Y los demás? Tío, son solo rumores. Igual no es verdad. No voy a perjudicar al resto de compañeros por nada. 
La atenuación en la producción de actos de habla en hablantes nativos y no nativos de español | Raquel Hidalgo

En las estrategias indirectas no convencionales (off record), que recogen dos casos (13\%), los hablantes se muestran ambivalentes en relación a su postura o línea de acción:

(42) Cuéntame que haríamos. ¿En qué has pensado? Dependiendo de cuál sea veo a ver qué hago.

Así pues, el informante deja en suspenso la respuesta, de aceptación o rechazo al ofrecimiento, y la aplaza a un momento posterior.

Tabla 6. Estrategias empleadas por los informantes no nativos en la situación 2.

\begin{tabular}{|l|l|l|l|l|}
\hline No nativos & \multicolumn{3}{|l|}{ Lo que piensan } & Lo que dicen \\
\hline Directa & 7 & $46 \%$ & 8 & $54 \%$ \\
\hline Indirecta convencional & 3 & $20 \%$ & 6 & $40 \%$ \\
\hline Indirecta no convencional & 5 & $34 \%$ & 1 & $6 \%$ \\
\hline Total & 15 & 100 & 15 & 100 \\
\hline
\end{tabular}

En los actos pensados de los no nativos, un 46\% expresa desacuerdo de forma directa y sin mitigación, con expresiones como "no puedo hacerlo" o "está mal". La estrategia directa no aparece con intensificadores, como en los nativos.

(43) No puedo quedarme a costa del perjuicio de otros.

(44) No puedo, es una traición.

Otro grupo, que asciende a un 20\%, en cambio, expresa el desacuerdo de forma indirecta y por tanto implícita, pero el desacuerdo puede entenderse por el enunciado:

(45) Es injusto, pero no puedo pensar sólo a mi situación. ¿Cómo haría él a no sentirse culpable?

Un grupo relativamente elevado (34\%) está constituido por los informantes no nativos que expresan lo que sienten de un modo indirecto más profundo, que no se identifica de forma clara con expresiones o formas que en español remitan al desacuerdo:

(46) Me parece arriesgado este plan porque tiene inseguridades morales. ¿Por qué me hace esta oferta?

(47) Menos mal que te tengo cerca.

(48) Está bien.

En estos enunciados, resulta difícil deducir la estrategia del hablante no nativo, puesto que en los dos primeros se percibe una evaluación negativa por parte del hablante, pero el informante no adopta una posición clara al respecto. En el último, el enunciado marca el acuerdo, de modo que se interpretaría como una aceptación del ofrecimiento, si bien la construcción (está bien) no resulta totalmente idiomática en español para ello (vale, de acuerdo, me parece bien) y el acuerdo no se refuerza con actos complementarios $u$ otras marcas de acuerdo. 
La atenuación en la producción de actos de habla en hablantes nativos y no nativos de español | Raquel Hidalgo

Los actos dichos muestran una distribución similar a los actos pensados. En un $54 \%$ de los casos, expresan el rechazo al ofrecimiento de forma directa, pero con mecanismos de mitigación, como actos de habla de apoyo que justifican el rechazo. En estos puede verse, por ejemplo, el uso del condicional, "me gustaría", "acabaríamos clavando"; también marcadores como "hombre", "bueno" o "mira" (alertadores). Otros actos de habla que aparecen como apoyo del rechazo son el agradecimiento (gracias por compartirlo), la disculpa (lo siento) y la sugerencia (tenemos que buscar otra solución).

(49) Me gustaría mantener mi trabajo pero no quiero dañar los otros, pues no, no puedo aceptar.

(50) Hombre, sí que lo has pensado muy bien y gracias por compartirlo conmigo pero según como lo veo yo, siguiendo este plan, acabaríamos clavando a los demás en la espalda, y esto no me apetece de verdad, tenemos que buscar otra solución.

(51) Gracias por tu ayuda, pero no puedo permitir eso, porque no quiero hacer daño a otros.

En las respuestas indirectas, que suponen el $40 \%$ de los casos, los informantes emplean un acto de habla que sugiere el rechazo del ofrecimiento pero no lo dice explícitamente:

(52) ¿No podemos buscar otra manera para sobrevivir juntos?

En el grupo de las estrategias indirectas no convencionales, encontramos actos que no dejan ver claramente el desacuerdo/rechazo o el acuerdo/aceptación del ofrecimiento:

(53) ¿Está bien hacer esto?

(54) No sé, me da cosa un poco...pero me parece buena idea para prepararnos antes de que algo nos perjudique.

(55) Me lo tengo que pensar mejor.

En los tres casos, el informante expresa un desacuerdo parcial e indirecto, pero suspende el momento de la decisión y la aplaza a otro momento, evitando rechazar el ofrecimiento y por tanto su impacto, reservándose la posibilidad de dar a su compañero otra contestación más adelante, en otro momento. En términos de cortesía, el informante aquí prefiere no expresar el desacuerdo/rechazo de forma clara, como tampoco la aceptación, por lo que la estrategia encubierta le permite mayor libertad de acción y un menor compromiso con el hablante.

\subsection{Situación 3}

En la Situación 3, los informantes han de expresar el desacuerdo con respecto a la compra que quiere realizar una amiga a la que acompañan. 
Tabla 7. Estrategias empleadas por los informantes nativos en la situación 3.

\begin{tabular}{|l|l|l|l|l|}
\hline Nativos & \multicolumn{2}{l|}{ Lo que piensan } & \multicolumn{2}{l|}{ Lo que dicen } \\
\hline Directa & 15 & $100 \%$ & 13 & $88 \%$ \\
\hline Indirecta convencional & - & - & 1 & $6 \%$ \\
\hline Indirecta no convencional & - & - & 1 & $6 \%$ \\
\hline Total & 15 & 100 & 15 & 100 \\
\hline
\end{tabular}

Los nativos expresan el desacuerdo en el pensamiento de forma directa, en todos los casos (100\%), con actos expresivos, que intensifican la valoración negativa y el desacuerdo. La intensificación es léxica (le queda fatal, esa blusa es fea, qué horror), ilocutiva con actos expresivos (qué mal gusto, qué horror, qué mal le queda, por dios). Otros intensificadores son interjecciones como "uy" y expresiones como "madre mía".

(56) Uy, qué fea.

(57) ¡Horror!

(58) Menudo horror, no le puede quedar peor.

En algunos casos, los informantes emplean mitigadores, como la interjección "ups" y "ay", "parecía otra cosa", "pobre" y la expresión meta-pragmática "a ver cómo se lo digo:

(59) ¡Ups, que mal queda puesta, parecía otra cosa en la percha!

(60) Ay, pobre, le queda fatal. A ver cómo se lo digo.

A diferencia de los actos intensificados, aquí los hablantes suavizan la valoración negativa, bien a través del sentimiento de empatía (ay pobre), bien formulando la necesidad de elaborar lingüísticamente el desacuerdo sin dañar su imagen (a ver cómo se lo digo).

Los actos dichos reproducen de manera bastante fiel los actos pensados, puesto que 13 de los 15 informantes, es decir un 88\% de los casos, expresan el desacuerdo de forma directa, y solo 2 informantes lo hacen con estrategias indirectas. Si bien expresan el desacuerdo de forma directa, en los actos dichos la evaluación negativa es más suave, se formula con expresiones como "no me convence", "no te queda bien", y aparece mitigada con expresiones de vaguedad o aparente indecisión, como "no sé", epistémicos como "yo creo" o "no me convence". Utilizan el apelativo "tía" con mucha frecuencia, como marca de cercanía juvenil y grupal, y un informante emplea "amor" como apelativo afectivo. Por tanto, la estrategia es la misma que en el acto pensado (expresar el desacuerdo de forma directa), pero los intensificadores no aparecen, y sí en cambio los mitigadores.

Además, aparecen actos complementarios que apoyan el desacuerdo, como la justificación, y que expresan cortesía, como la sugerencia, a través de la cual el informante ofrece opciones y refuerza lazos de camaradería con su compañera. 
(61) No está mal, pero creo que te favorecen más otros colores, además, te hace una cosa muy rara en la espalda.

(62) A ver, no es que te quede mal, pero no te favorece mucho.

Por tanto, en la situación 3, no se produce una diferencia sustancial entre lo que piensan y lo que dicen. El acto pensado es la reacción espontánea y contiene intensificadores que refuerzan la evaluación negativa y por tanto el descuerdo. En el acto dicho, en cambio, los hablantes emplean la atenuación para suavizar el desacuerdo. Por tanto, los informantes nativos no se desaniman a la hora de expresar su opinión sinceramente, pero son conscientes (conciencia pragmática) de que este ha de ser enunciado atendiendo las imágenes del interlocutor, y que por tanto ha de expresarse con cortesía. De ahí que los actos pensados sean directos y sin cortesía, pero con intensificadores; y los actos dichos, sean en cambio, directos y también indirectos, pero con mitigación, y con estrategias de cortesía, casi todas, positiva (acercamiento y familiaridad).

Tabla 8. Estrategias empleadas por los informantes no nativos en la situación 3.

\begin{tabular}{|l|l|l|l|l|}
\hline No nativos & Lo que piensan & \multicolumn{2}{l|}{ Lo que dicen } \\
\hline Directa & 14 & $94 \%$ & 8 & $54 \%$ \\
\hline Indirecta convencional & 1 & $6 \%$ & 4 & $26 \%$ \\
\hline Indirecta no convencional & - & - & 3 & $20 \%$ \\
\hline Total & 15 & 100 & 15 & 100 \\
\hline
\end{tabular}

Los informantes no nativos expresan el desacuerdo en los actos pensados también en una gran mayoría (94\%), pero no con la misma contundencia que los hablantes nativos. Emplean el desacuerdo directo, evaluando negativamente al oyente con intensificadores que añaden expresividad a la reacción: qué horror, qué fea, horrenda, le queda fatal, fatal, no le queda nada bien. Utilizan también interjecciones con valor intensificador, si bien no son las mismas que los nativos:

(63) ¡Aaaah! ¡Qué mal! Madre mía, jes terrible! ¡¿Cómo puede pensar en comprárselo?! Madre mía, iqué falta de gusto!

(64) ¡Eeeiihhh! (expresión de asco) ¡Pero qué fea se ve en esta!

Sin embargo, en muchos casos mitigan la evaluación negativa:

(65) No le queda nada bien, voy a hacerle unas sugerencias

(66) Vaya, sí que es barata, pero por favor, no te la compres. No te queda nada bien.

Uno de los informantes expresa el acuerdo de forma indirecta, aunque el desacuerdo mitigado se comprende implícitamente:

(67) Parece un poco campestre, hay que decírselo.

Además, la mitigación se expresa como comentarios meta-pragmáticos sobre la línea de actuación más adecuada para no herir la imagen positiva del oyente y poder expresar el 
desacuerdo de una manera cortés, a través de las sugerencias. Los mitigadores "voy a hacerle unas sugerencias" y "hay que decírselo" sugieren que el acto del desacuerdo es necesario, porque actúa en beneficio del oyente, y por tanto no resulta tan impositivo si se logra elaborar lingüísticamente el mismo de un modo que salvaguarde la imagen de ambos y atienda la cortesía.

En los actos dichos, la estrategia directa baja a un 54\% de los casos, y el resto de informantes opta por estrategias indirectas convencionales en un 26\% y por estrategias encubiertas, off record, en un 20\% (3 casos). Cuando emplean la estrategia directa, expresan el desacuerdo de forma clara, pero emplean mitigadores para no herir la imagen positiva del otro:

(68) Querida, no me parece bien esta blusa, te queda un poco rara, piénsalo antes de comprártela.

(69) Ah, bueno, este modelo no me gusta tanto, la verdad. ¿Por qué no te pruebas esa blusa de ahí? Creo que te quedaría mucho mejor con tu tono de piel.

Emplean alertadores con valor de mitigación (ah, bueno, hombre, oye), apelativos (querida), aunque no los mismos que los nativos (tía). Acompañan el desacuerdo de actos complementarios que suavizan el desacuerdo y que estrechan lazos de camaradería (cortesía positiva), o bien ofrecen opciones, sugieren una línea de acción alternativa (¿Por qué no te pruebas...?).

Las estrategias indirectas convencionales, que aparecen en un 20\% de los casos, se articulan a través del acto de la sugerencia, que se comprende implícitamente como desacuerdo, pero sin llegar a formularlo o hacerlo explícito.

(70) Antes de decidir ¿no quieres probar alguna otra? Creo que la de azul también te quedaría muy bien, quizás más que ésta.

Además, en 3 casos (20\%), las respuestas no dan indicios claros de la posición del hablante, que se oculta en la estrategia encubierta:

(71) Esta es la que te dije que yo iba a comparar.... está bonita, ¿ay qué sí? También voy a probar, ¿te importa tener una blusa igual que la mía?

(72) ¿Sabes qué? Esta blusa me resulta muy parecida a la que te pusiste para ir al cine el jueves pasado...

En los dos casos se evita el desacuerdo y se deja al interlocutor que decida o se irrumpe en su línea de acción, pero aportando otros argumentos o razones, que no dan indicios del desacuerdo.

\subsection{Situación 4}

En la situación 4, los informantes han de reaccionar a una sorpresa presentada por la persona con la salen desde hace poco tiempo, una invitación a un concierto que no les 
La atenuación en la producción de actos de habla en hablantes nativos y no nativos de español | Raquel Hidalgo

gusta. Si bien la relación es de intimidad y por tanto hay familiaridad entre los interlocutores, el hecho de que la relación no esté consolidada puede añadir un factor de vulnerabilidad en las imágenes de los interlocutores.

Tabla 9. Estrategias empleadas por los informantes no nativos en la situación 5.

\begin{tabular}{|l|l|l|l|l|}
\hline No nativos & Lo que piensan & \multicolumn{2}{l|}{ Lo que dicen } \\
\hline Directa & 13 & $74 \%$ & 1 & $6 \%$ \\
\hline Indirecta convencional & 2 & $26 \%$ & 6 & $40 \%$ \\
\hline Indirecta no convencional & - & - & 8 & $54 \%$ \\
\hline Total & 15 & 100 & 15 & 100 \\
\hline
\end{tabular}

En sus pensamientos, los hablantes nativos expresan de forma directa su rechazo a la sorpresa, en un $74 \%$ de los casos. En los actos pensados, articulan su reacción como una queja o evaluación negativa, para lo que emplean intensificadores como interjecciones (buff, puff) que indican fastidio, carga y evaluación negativa, exclamativas como "qué horror" o intensificadores internos, "menudo coñazo", "este coñazo de grupo"; también emplean mitigadores como "bueno, el pobre", que marcan empatía con el hablante. Mientras que los intensificadores aumentan la fuerza de la queja y de la evaluación negativa, los mitigadores suavizan el rechazo:

(73) Menudo coñazo de plan me espera.

(74) Uff, bueno el pobre... maldita la gana.

(75) (Risas) Vaya mierda de grupo, pero por amor, lo que haga falta.

En este último enunciado, "vaya mierda" intensifica la queja, pero las risas y el acto secundario, "pero por amor, lo que haga falta" mitigan la evaluación negativa.

En un porcentaje muy alejado, un $26 \%$ de los informantes expresa la queja de forma indirecta; no se expresa aunque se entiende implícitamente por "lo que cuenta" y "ha podido preguntarme antes":

(76) Bueno lo que cuenta es que voy con él y los pequeños detalles me encantan.

(77) ¡Oh, qué detalle más bonito, pero ha podido preguntarme antes!

El enunciado es interesante porque se entiende implícitamente el desacuerdo (no le gusta el regalo), pero en su reacción el hablante emplea una estrategia de acercamiento hacia el oyente (cortesía positiva, en Brown y Levinson), al reconocer lo positivo del comportamiento del oyente (lo que cuenta es que voy con él) y lo proyecta sobre sí mismo (me encantan).

De forma similar, en el enunciado (77), el hablante emplea un acto expresivo, "oh qué detalle más bonito", en el que muestra su reacción positiva, que mitiga la expresión indirecta del desacuerdo (pero ha podido preguntarme antes), en el que se entiende implícitamente el desacuerdo aunque no se dice. 
Los actos dichos reflejan un comportamiento completamente distinto. Solo una de las informantes (6\% de los casos) contesta de forma directa, rechazando la invitación. Para ello, se sirve de varios mitigadores, que atenúan el rechazo y se acercan al interlocutor afectivamente para no herir su imagen positiva:

(78) Cariño, que es un detalle precioso, pero que no me gusta nada ese tipo, en serio, si quieres llévate a tu amigo que le encanta, y ya vamos tú y yo a cenar o a algo de eso, eres un amor cariño pero para estar ahí amargada mejor no voy.

Aquí la informante expresa el desacuerdo ("no me gusta nada ese tipo"), que mitiga con el apelativo afectivo "cariño" y con un acto de refuerzo, "es un detalle precioso"; mitiga el rechazo, además, con los actos secundarios o de apoyo, la sugerencia (llévate a tu amigo que le encanta, "ya vamos tú y yo a cenar o algo de eso"), "eres un amor cariño". Emplea las estrategias de acercamiento o cortesía positiva, para poder mitigar el posible daño a la imagen positiva del otro.

Se puede considerar que el agradecimiento es una forma indirecta convencional de aceptación de un regalo o una invitación:

(79)

a. ¿Quieres venir al cine?

Sí, gracias.

b. Toma, te he comprado esto.

Ay, muchas gracias, qué detalle.

Pero en estos enunciados (inventados), se marca la aceptación: en el primer caso, con el "sí". En el segundo, se acepta el regalo, aunque no se expresa la opinión acerca de él (me gusta/no me gusta). La expresión de la opinión del regalo es un hecho secundario con respecto a la aceptación del mismo. Por tanto, el hablante puede aceptar el regalo aunque este no le guste. Con este movimiento, atiende a una de las facetas del acto de habla (el regalo o invitación han de ser aceptadas o rechazadas), pero no a la otra (han de gustar al receptor, por tanto el receptor debería dar indicaciones de que le ha gustado).

La mayoría de las respuestas son, por tanto, indirectas; de ellas, el 40\% se corresponden con formas indirectas convencionales o reconocibles, y en un porcentaje más elevado, hasta un 54\% de los casos, con estrategias indirectas encubiertas, no convencionales.

En el primer grupo, los informantes emplean el agradecimiento, y por tanto aceptan el regalo e invitación, al menos inicialmente. A continuación, expresan el desacuerdo mitigado a través de una justificación (mitigación ilouctiva: la verdad es que...) y con mitigadores internos (precisamente), pero mediante los actos complementarios (estoy segura de lo que pasaremos genial, ¿tienen buen directo?), lo importante es la compañía) se entiende la aceptación indirecta a la invitación.

(80) ¡Muchas gracias! La verdad es que no es precisamente mi grupo favorito, pero estoy segura de que lo pasamos genial. 
La atenuación en la producción de actos de habla en hablantes nativos y no nativos de español | Raquel Hidalgo

(81) ¡Gracias! Si quieres vamos, pero no suelo escuchar mucho al cantante, aun así jlo importante es la compañía! Aunque a mí los planes de pareja no me gustan mucho, iya me irás conociendo!

Por tanto, recapitulando, este grupo acepta la invitación, pero expresa cierto rechazo mitigado al objeto de la invitación, que se entiende implícitamente aunque no se dice.

Por último, el grupo más numeroso (54\%) emplea estrategias indirectas no convencionales, encubiertas, en un grado mayor de indirectez:

(82) Como me conoces jeh! -dijo entre risas con sarcasmo amoroso.

(83) Muchas gracias, suena divertido nos lo pasaremos bien (irónico), pero la próxima vez coméntaselo a alguno de mis amigos para que te den su opinión (risas).

Los informantes emplean la ironía o el humor para ofrecer pistas del desacuerdo o evaluación negativa, también las risas cumplen la función de mitigar el desacuerdo, marcándolo indirectamente. Podemos decir, por tanto, que en estos casos, los informantes intentan transmitir algunas pistas del desacuerdo, pero no llegan a articular un rechazo, como tampoco servirse de un acto secundario (sugerencia) para eludir el desacuerdo o sugerir otra línea de acción que les permita salvaguardar la imagen del otro al mismo tiempo que ser cortés.

La situación 5 muestra una situación comunicativa en la que el acto tiene un grado de imposición más alto de lo esperado, porque se trata de una relación que está construyendo la intimidad y la confianza, y en esa fase de la relación, es particularmente importante atender las necesidades de imagen (positiva) del otro. Solo en un caso, la persona se ha atrevido a decir lo que pensaba abiertamente, mientras que los demás han optado mayoritariamente por sacrificar la expresión del descuerdo en favor de guardar la imagen del otro. Por tanto, en esta situación existe una diferencia sustancial entre lo pensado y lo dicho, puesto que lo pensado expresa claramente la reacción negativa a la situación, o la ambivalencia que produce la misma, mientras que en lo dicho se hace patente la prioridad de salvaguardar la imagen del otro, en beneficio de una relación que se está consolidando, sobre la expresión sincera de la opinión personal.

Tabla 10. Estrategias empleadas por los informantes no nativos en la situación 5.

\begin{tabular}{|l|l|l|l|l|}
\hline No nativos & Lo que piensan & \multicolumn{2}{l|}{ Lo que dicen } \\
\hline Directa & 10 & $67 \%$ & 3 & $20 \%$ \\
\hline Indirecta convencional & 1 & $7 \%$ & 4 & $26 \%$ \\
\hline Indirecta no convencional & 4 & $26 \%$ & 8 & $54 \%$ \\
\hline Total & 15 & 100 & 15 & 100 \\
\hline
\end{tabular}

Los hablantes no nativos expresan su descontento con la sorpresa de su amigo/a en un $67 \%$ de los casos, por tanto, en menor número que los nativos. En un $20 \%$ de los casos expresan formas indirectas y en un $13 \%$ no llegan a expresar su disgusto. 
Expresan de forma directa el desacuerdo, o bien como quejas o reproches, en ocasiones con intensificación, pero de menor fuerza, variedad y número que los nativos.

(84) Mierda. Me da mucha pereza este grupo.

(85) Esto qué es, no me gusta nada este grupo, no estamos en el mismo mundo.

También expresan su rechazo de forma directa, pero sin intensificación:

(86) No quiero ir.

Las estrategias encubiertas ascienden a un $26 \%$ de los casos, un porcentaje elevado para los actos pensados. En estos casos, los informantes expresan fundamentalmente sorpresa, pero esta no da indicios claros de rechazo o desacuerdo. La sorpresa no se marca como positiva ni negativa (aunque entendemos que "menuda" sería negativa), como tampoco se deja ver la línea de acción que seguirá el informante.

(87) ¡CARAMBA!

(88) Menuda sorpresa

(89) Ummmm

En un caso, los informantes expresan el desacuerdo de forma indirecta, pero aquí sí puede identificarse por la forma empleada, esa marca. En este caso, la evaluación negativa mitigada se entiende como desacuerdo implícito pero futura aceptación de la invitación.

(90) Bueno...no es la mejor elección del mundo.... Pero bueno.

En los actos dichos, la mayoría de los hablantes no nativos opta por no realizar el acto o realizarlo de forma encubierta, es decir, en la estrategia off record. Existe de nuevo variación importante entre lo que piensan y lo que dicen, pero en menor medida que en los nativos. En los no nativos, las formas pensadas y las formas dichas no distan sustancialmente En el caso del regalo-invitación, solo un 3\% expresa claramente rechazo o desacuerdo; un $26 \%$ emplea formas convencionales pero indirectas, en las que se sobreentiende el rechazo o desacuerdo aunque no se diga explícitamente; en un 54\% de los casos, en cambio, el enunciado no deja ver que haya desacuerdo o rechazo, o bien porque no se ha expresado en absoluto (opta por no decirlo) o bien porque la línea de acción del hablante no se deduce claramente (estrategia encubierta, off record).

Veamos algunos ejemplos de cada caso.

(91) ¡Gracias! No me gusta mucho este cantante, pero si quieres ir, te acompaño.

(92) Ay, iqué majo eres! ¡Gracias! Lo que pasa es que, te lo tengo que decir, este grupo, la verdad es que no me gusta mucho... No sé, si quieres, podemos ir, por supuesto, pero es que... igual podemos hacer otra cosa, ir a cenar, ¿por ejemplo? 
En el primer caso, el agradecimiento se entiende como respuesta convencional a una invitación o regalo. Pero después expresa su desacuerdo, "no me gusta mucho este cantante", con el mitigador interno (mucho), y con los actos secundarios, "pero si quieres ir, te acompaño" que se entiende como sugerencia. El informante ofrece opciones y una línea de acción alternativa, en la que incluye al hablante y oyente (estrategia inclusiva de cortesía positiva).

En la mayoría de los casos, los hablantes no nativos no llegan a expresar el desacuerdo o rechazo a la invitación, sino que la aceptan, aparentemente como si no hubiera problema alguno con ella:

(93) Gracias por tu invitación. Me siento conmovida. Voy a disfrutar mucho de este concierto.

(94) ¡Gracias! ¡Qué dulce que eres! En realidad no conozco este grupo, ipero me gustaría escucharlo contigo!

(95) Ay muchas gracias. Me gusta mucho.

En estos casos, el informante considera que expresar el desacuerdo comporta un riesgo de daño a la imagen positiva del otro, y prefiere no correr ese riesgo, que podría interferir negativamente en una relación de intimidad que comienza. Por tanto, los hablantes no nativos optan por no expresar el desacuerdo y aceptar la invitación, omitiendo por completo su opinión personal. De ahí se deduce que el grado de imposición del acto se percibe como elevado, y que en esta situación se valora más la posibilidad de salvaguardar la imagen del otro y con ello la relación, que la de expresar el punto de vista propio.

Por último, otro grupo de respuestas indirectas dejan implícito el rechazo, pero no las razones del mismo:

(96) Gracias, tengo que trabajar aquella noche.

En este caso, rechazan la invitación, pero la excusa, que es una forma convencionalizada de rechazo a una invitación, no da indicios de los verdaderos motivos del rechazo, sino que los oculta.

\section{ESTRATEGIAS DE REALIZACIÓN DE ACTOS EN HABLANTES NATIVOS Y NO NATIVOS}

En la comparación entre nativos y no nativos, ha de destacarse que las estrategias y distribuciones de las mismas son similares en los dos grupos, lo cual refleja una conciencia pragmática similar en los dos casos, así como el hecho de que las respuestas, tanto pensadas como elaboradas, se articulan en virtud de estrategias comunicativas, que atienden al cálculo o estimación de cuáles son los parámetros sociales e interpersonales que se ponen en juego en cada situación. En los dos casos, además, los procesos de pensamiento contienen más estrategias directas, intensificadores, lo que subraya el carácter emocional y espontáneo de los actos pensados, así como su función preparatoria de los actos de habla. En las formas dichas, en cambio, aparecen las estrategias indirectas convencionales, los distintos mecanismos de atenuación, manifestación de la conciencia 
pragmática de los hablantes, que construyen elaboraciones lingüísticas complejas para poder ofrecer respuestas no preferidas sin herir la imagen del otro.

En los no nativos, la distancia entre el pensamiento y el acto dicho es menor; las cifras son similares, y los hablantes no nativos no expresan la diferencia entre los dos procesos con la misma nitidez. Además, es más numeroso el empleo de las estrategias indirectas no convencionales, "off record," en la terminología de Brown y Levinson (1987); estos actos son ambiguos, en el sentido de que no expresan claramente la aceptación o el rechazo. Aquí los hablantes no nativos eluden tomar una posición concreta con respecto al ofrecimiento inicial, o bien transfieren estrategias indirectas de su lengua materna, para expresar rechazo de forma implícita, mitigada, aunque en español no resultan idiomáticas y por tanto no son siempre interpretables.

También se echan en falta las convenciones de forma y uso de los actos indirectos en los hablantes no nativos. Emplean formas de español correcto, pero que no se corresponden con las expresiones que han fijado su uso convencional en determinados actos. Así ocurría en la situación 1: los nativos convertían la queja de sus actos pensados en petición indirecta en los actos dichos, mientras que los no nativos no distinguían claramente las construcciones sintácticas y expresiones propias de cada uno, y expresaban la petición de forma agresiva y confrontacional. En la situación 3, los no nativos empleaban menos intensificadores en los actos pensados, y apenas utilizan apelativos como "tía" o formas que se empleen entre amigas o compañeras, salvo "querida", que no es idiomático entre chicas jóvenes españolas. Empleaban interjecciones, pero no las que emplean los nativos. En la situación 4, se advierte menor distancia entre lo pensado y lo dicho en los no nativos. Mientras que los nativos expresan sus pensamientos como rechazo o desacuerdo, y emplean intensificadores que dotan expresividad a su rechazo, los no nativos expresan evaluación directa pero sin intensificarla, y cuando lo hacen, no emplean las expresiones o actos idiomáticos. La intensificación es menor y menos variada, o completamente ausente.

En los actos dichos, los hablantes nativos expresan el desacuerdo con mitigadores, tanto ilocutivos (actos indirectos) como internos (proposicionales) y externos (actos de refuerzo). Por tanto, la mitigación es una forma habitual en estos casos de expresar el desacuerdo. En algunos casos, no aceptan la invitación, pero mitigan el rechazo y ofrecen alternativas en forma de sugerencia. En otros casos, sí aceptan la invitación, aunque dejan entrever parte del desacuerdo.

En los hablantes no nativos, en cambio, se expresa la misma estrategia, pero llama la atención la simplicidad y escasa elaboración de los enunciados. Son menores los mitigadores, y menos variados. Por otro lado, abundan los enunciados que aceptan la invitación sin más, sin expresar otros actos. En estos, por tanto, no es deducible si hay desacuerdo o rechazo hacia el objeto del regalo. Pensamos que los hablantes no nativos o bien dan mayor prioridad a salvaguardar la imagen del otro, o bien no han sabido articular una respuesta compleja en la que acepten la invitación, pero expresen una parte del rechazo.

Puesto que los informantes no compartían la lengua materna sino que eran de orígenes distintos (chinos, ucranianos, rusos, alemanes, franceses, italianos), resulta aventurado establecer la influencia de la lengua materna en las realizaciones de los actos y en el empleo 


\section{normas}

La atenuación en la producción de actos de habla en hablantes nativos y no nativos de español | Raquel Hidalgo

de mecanismos de atenuación; resulta plausible pensar que puede existir transferencia pragmática en algunos casos, pero sería necesario centrar el estudio en un grupo homogéneo para comprender cuál es el papel de la lengua materna.

\section{CONCLUSIONES}

El estudio comparado de los actos de habla entre informantes nativos y no nativos de español se ha llevado a cabo a través de una metodología de role-play en dos movimientos, los actos pensados y los actos dichos, para poder observar el proceso de elaboración de los actos de habla, en concreto de las respuestas despreferidas en varias situaciones comunicativas. La mitigación se muestra como un fenómeno natural que tiene su origen en la elaboración misma del acto de habla, en relación con el análisis que realiza el hablante de las variables contextuales.

Tanto los hablantes nativos como los no nativos muestran conciencia pragmática y por tanto estrategias similares a la hora de proporcionar una elaboración lingüística adecuada en cada situación. Los distintos procedimientos de mitigación están presentes en los dos grupos. Sin embargo, aunque los hablantes no nativos conocen las estrategias pragmáticas, no siempre distinguen bien entre los distintos actos de habla, por ejemplo entre queja y petición indirecta; además, les faltan las expresiones, construcciones y fraseología idiomáticas del español; no siempre encuentran la formulación de actos de habla que se identifican en español con las convenciones de forma y de uso para los actos indirectos; tampoco conocen los procedimientos de mitigación en la variedad y elaboración suficientes para lograr mitigar los desacuerdos o rechazos.

Pese a las limitaciones de esta investigación, los resultados muestran que se trata de un área importante de trabajo que puede arrojar luz sobre los procesos de adquisición de la competencia pragmática, así como la inclusión de estos hallazgos en el diseño de actuaciones didácticas.

\section{REFERENCIAS BIBLIOGRÁFICAS}

AlbeLDA, Marta et al. (2014): «Ficha metodológica para el análisis pragmático de la atenuación en corpus discursivos del español», Oralia, 17, 7-63.

Álvarez Muro, Alexandra y Carolina JOVEn BeSt. (2005): «Manipulación y seducción en conversaciones entre mujeres de Mérida», en Diana Bravo (coord.), Estudios de la (des)cortesía en español, Buenos Aires, Dunken, 119-145.

BALlesteROS, Francisco José (2002): «Mecanismos de atenuación en español e inglés. Implicaciones pragmáticas en la cortesía». Círculo de Lingüística Aplicada A la Comunicación, 11, http://www.ucm.es/info/circulo/no11/ballesteros.htm Accessed 2 June 2008

BLUM-KULKA, Shoshana (1987): «Indirectness and politeness in requests: same or different?», Journal of Pragmatics, 11, 1, 131-146.

BLUM-KULKA, Shoshana et. Alii (1989): Cross-Cultural Pragmatics: Requests and Apologies, Norwood, Ablex.

Brown, Penelope y Stephen LeVInson (1987): Politeness. Some Universal in Language Use, Cambridge, Cambridge University Press.

BRIZ, Antonio (2005): «Naturaleza de la estrategia atenuadora en la conversación cotidiana española», en Diana Bravo (coord.), Estudios de la (des)cortesía en español. Buenos Aires, Dunken, 53-93.

CAFFI, Claudia (2007): Mitigation, Amsterdam, Elsevier.

ESCANDELL VIDAL, María Victoria (1995): “Cortesía, fórmulas convencionales y estrategias indirectas», Revista Española de Lingüística, 25 (1), 31-66. 


\section{normas}

La atenuación en la producción de actos de habla en hablantes nativos y no nativos de español | Raquel Hidalgo

FÉLIX-BRASDEFER, Julio César. (2004): «La mitigación en el discurso oral de mexicanos y aprendices de español como lengua extranjera», en Diana Bravo y Antonio Briz (eds.), Pragmática sociocultural: estudios sobre el discurso de cortesía en español. Barcelona, Ariel, 285-298.

FÉLIX-BRASDEFER, Julio César. (2010): «Data collection methods in speech act performance: DCTs, role plays, and verbal reports». En Alicia Martínez-Flor y Esther Usó-Juan (eds.), Speeh Act Performance. Theoretical, empirical and methodological issues, Amsterdam, John Benjamins, 41-57.

GELUYKENS, Ronald y Anjia BREUER (2007): «Variation in British and American English Requests: A contrastive analysis», en Bettina Kraft y Ronald Geluykens eds., Cross-Cultural Pragmatics and Interlanguage English, Muenchen, Lincom, 107-142.

GASS, Susan M. y Joyce NEU Eds. (1995): Speech Acts across Cultures. Berlin/Nueva York, Mouton de Gruyter.

HAVERTAKE, Henk (2004): «El análisis de la cortesía comunicativa: categorización pragmalinguistica de la cultura española», en Diana Bravo y Antonio Briz eds, Pragmática socio-cultural: estudios sobre el discurso de cortesía en español, Barcelona, Ariel, 55-66.

HICKEY, Leo (1991): "Comparatively polite people in Spain and Britain», Association for Contemporary Iberian Studies 4(2), 2-7.

Houck, Noel y Susan GASS (1995): «Non-native refusals: A methodological perspective», en Susan M. Gass y Joyce Neu eds. Speech Acts across Cultures, Berlin/Nueva York, Mouton de Gruyter, 45-65.

KASPER, Gabriele y Merete DAHL (2002): «Research methods in interlanguage pragmatics», Studies in Second Language Acquisition, 13, 215-247.

KASPER, Gabriele y Shoshana BLUM-KULKA (1993): «Interlanguage pragmatics: an introduction», en Gabriele Kasper y Shoshana Blum-Kulka eds, Interlanguage Pragmatics, Oxford, Oxford University Press, 3-20.

KASPER, Gabriele (2000): «Data Collection in Pragmatics Research», en Helen Spencer-Oatey ed. Culturally Speaking: Managing Rapport Across Cultures, London, Continuum, 316-341.

KRAFT, Bettina y Ronald GELUYKENS eds (2007): Cross-Cultural Pragmatics and Interlanguage English, Muenchen, Lincom.

LEECH, Geoffrey (1983): Principles of Pragmatics, London, Longman.

LEVINSON, Stephen (1983): Pragmatics, Cambridge, Cambridge University Press.

LORENZO DUS, Nuria (2001): "Compliment responses among British and Spanish university students: A contrastive study", Journal of pragmatics, 33, 107-127.

LORENZO Dus, Nuria y Paul MeARA (2004): «Role-plays and the assessment of oral proficency in Spanish», en Rosina Márquez Reiter y Maria Elena Placencia eds, Current Trends in the Pragmatics of Spanish, Amsterdam, John Benjamins, 79-99.

MÁRquez ReIter, Rosina. (2000): Linguistic Politeness in Britain and Uruguay, Amsterdam, John Benjamins.

Placencia, María Elena y Diana Bravo (2002): Actos de habla y cortesía en español, Munich, LINCOM.

SEARLE, John (1969): Speech Acts. An Essay in the Philosophy of Language, Cambridge, Cambridge University Press.

SIFIANOU, MARIA (1992): Politeness phenomena in England and Greece: A cross-cultural perspective, Oxford, Clarendon Press.

THOMAS, Jenny (1996): Meaning in Interaction: An Introduction to Pragmatics, Londres, Longman.

ZUFFEREY, Sandrine (2015): Acquiring Pragmatics, Londres, Routledge. 